\title{
Long-Term (1982 - 2012) Summertime Sea Surface Temperature Variability in the Taiwan Strait
}

\author{
Ming-An Lee ${ }^{1,2}$, Yi-Chun Kuo ${ }^{1, *}$, Jui-Wen Chan ${ }^{3}$, Yu-Kai Chen ${ }^{4}$, and Sheng-Yuan Teng ${ }^{1}$ \\ ${ }^{1}$ Department of Environmental Biology and Fishery Science, National Taiwan Ocean University, Keelung, Taiwan, R.O.C. \\ ${ }^{2}$ Center of Excellence for Oceans, National Taiwan Ocean University, Keelung, Taiwan, R.O.C. \\ ${ }^{3}$ Taiwan Ocean Research Institute, Kaohsiung City, Taiwan, R.O.C. \\ ${ }^{4}$ Taiwan Fishery Research Institute, Keelung, Taiwan, R.O.C.
}

Received 31 December 2013, revised 11 March 2014, accepted 2 December 2014

\begin{abstract}
Long-term (1982 - 2012) advanced very-high-resolution radiometer (AVHRR) data collected at a resolution of $0.04^{\circ}$ clearly indicated sea surface temperature (SST) warming and variations associated with El Niño and Southern Oscillation (ENSO) in the Taiwan Strait (TS) during the summer. From 1982 - 2012 the spatially averaged warming trend in the TS was $0.057^{\circ} \mathrm{C} \mathrm{y}^{-1}$. However, during the last 10 years the warming phenomenon appears to have halted and a slight cooling rate $\left(0.03^{\circ} \mathrm{C}^{-1}\right)$ was observed. The monthly SST transition from June - July became increasingly sharp. The first mode $(70 \%)$ of the empirical orthogonal function (EOF) analysis indicated an SST warming trend. The warming occurred primarily in the eastern strait. The warming slowed down and considerable inter-annual variation occurred in the period after 1994. EOF results applied to the data between 1994 - 2012 showed that the first EOF mode (55\%) revealed a warming pattern, whereas the second EOF mode (12\%) revealed a pattern that explained the inter-annual variation in the SST, which was strongly correlated with the wind speed. Strong winds enhanced the upwelling along the China coast, eastern Taiwan Banks (TWB) and southern Peng-Hu Islands, whereas the SST in eastern TS increased because of increased warm water transport from the South China Sea. The inter-annual variation in the southwesterly wind could be affected by both ENSO and the background Pacific Decadal Oscillation (PDO) phase. The strongest upwelling in the TS tended to occur when ENSO and PDO were in phase associated with the southwesterly wind.
\end{abstract}

Key words: Sea surface temperature, El Niño and Southern Oscillation (ENSO), Taiwan Strait, Climate change

Citation: Lee, M. A., Y. C. Kuo, J. W. Chan, Y. K. Chen, and S. Y. Teng, 2015: Long-term (1982 - 2012) summertime sea surface temperature variability in the Taiwan Strait. Terr. Atmos. Ocean. Sci., 26, 183-192, doi: 10.3319/TAO.2014.12.02.03(EOSI)

\section{INTRODUCTION}

The Taiwan Strait (TS), a narrow channel separating China and Taiwan, connects the East China Sea (ECS) and the South China Sea (SCS) and thereby plays a critical role in water transfer and advective heat redistribution between the two seas. Although the TS is small, being $170-370 \mathrm{~km}$ wide and approximately $330 \mathrm{~km}$ long, it contains at least four upwelling regions that contribute to key fishing grounds during the summer (Hu et al. 2003).

The TS orientation is approximately southwest to northeast. Currents in the TS typically flow to the northeast because of a large permanent northeastward pressure

\footnotetext{
* Corresponding author

E-mail:f94241101@ntu.edu.tw
}

gradient (Jan et al. 2002; Wu and Hsin 2005). The variation in current circulation in the strait is dominated by the East Asian monsoon, which blows northeasterly in the winter and southwesterly in the summer. The summer monsoon, with wind stress less than $0.025 \mathrm{~N} \mathrm{~m}^{-2}$ (sea surface wind speed $<4 \mathrm{~m} \mathrm{~s}^{-1}$ ), is weaker than the winter monsoon. However, given the combination of northward pressure gradient and the southwesterly monsoon, the largest volume of water is transported every year during the summer $(1.6-2.3 \mathrm{~Sv})$. Most of this water is contributed by the warm SCS water (Jan et al. 2006). The TS topography is complex (Fig. 1) in that it is deepest in the southeast and gradually shoals northward. The deep Peng-Hu Channel (PHC; > $800 \mathrm{~m}$ ) is located in the southern TS. To the west of the PHC is 
the shallow Taiwan Banks (TWB). Numerous summertime upwelling zones have been identified using remote sensing and hydrological and biological observations (Hong et al. 1991; Lan et al. 2009). According to Tang et al. (2002), two major upwelling areas exist in the TS, one roughly east of the TWB and the other along the China coastal region.

In relation to the inter-annual variation in summertime sea surface temperature (SST) in the TS, Tang et al. (2004) investigated the variation in these upwelling regions during 1987 - 1998 and reported that the variations can occur in either strength or size. Hong et al. (2009) suggested that the El Niño and Southern Oscillation (ENSO) effects were responsible for the inter-annual variability in the upwelling. Previous studies focused only on the variations in the upwelling areas. The long-term summertime SST variation characteristics remain unknown. In addition to climate variations such as ENSO, global ocean warming has been identified as one of the key issues in the ESC and SCS. Belkin (2009) reported a rapid warming of $1.22^{\circ} \mathrm{C}$ between $1982-2006$ in the ECS Large Marine Ecosystem (LME), and a median warming of $0.44^{\circ} \mathrm{C}$ in the SCS LME. However, the ocean warming rate and its seasonality in the TS, located between the ECS and SCS, have rarely been investigated. The topography in the TS can modify the SST variability associated with climate change through topography-flow interactions, which include the upwelling phenomenon. Therefore, longterm high-resolution satellite data are required to understand the variations in the summertime SST features in the TS.

This study used 31 years of satellite SST data to explore the summertime SST changes in the TS with the goal of providing information that can benefit fisheries and marine biological research. Empirical orthogonal function (EOF) analysis was applied to simplify and quantify spatial and temporal SST variability. Section 2 briefly introduces the satellite data and EOF method. Section 3 presents the satellite data analy- sis results. Section 4 discusses the study results. Discussions and a summary are given in sections 4 and 5 , respectively.

\section{DATA AND METHOD}

Daily satellite SST images from June 1982 to August 2012 were collected from a collection of images captured using advanced very-high-resolution radiometer (AVHRR) sensors placed on National Oceanic and Atmospheric Administration(NOAA) satellites (http://www .class.ngdc.noaa. gov). Images were also collected from the regional AVHRR data library at National Taiwan Ocean University (NTOU), Keelung, Taiwan. The navigation and cloud-detection techniques developed by Sakaida and Kawamura (1992) were used. The multichannel sea surface temperature (MCSST) algorithm (McClain et al. 1985) was used to produce SST images at a spatial resolution of $4 \mathrm{~km}(1982-1993)$ and $1.1 \mathrm{~km}(1994-2013)$. The data for a $4 \times 4(\mathrm{~km})$ grid were interpolated on to a $1 \times 1(\mathrm{~km})$ grid. Lee et al. (2005) validated the SST algorithm by comparing the 1998 - 2002 AVHRRbased MCSSTs with the in situ data. The MCSSTs exhibited small biases of $0.009^{\circ} \mathrm{C}$, with root mean square deviations of $0.64^{\circ} \mathrm{C}$. For the purpose in this study, only the data collected during the summer months (June - August) were used. The monthly SST data were generated by arithmetically averaging all of the available scenes in each month on a pixel-by-pixel basis (excluding missing data and clouds). Two images collected in June 1982 and August 1988 were omitted to prevent the result from being biased because the cloud-free pixel coverage of these images was $<85 \%$. Thus, 31 years of monthly SST data, ranging between $115-122^{\circ} \mathrm{E}$ and $22-26^{\circ} \mathrm{N}$ comprising 321201 spatial data points, were available for use in studying the changes in summer SST patterns in the TS that occur in response to global warming trends and other climatic variations.

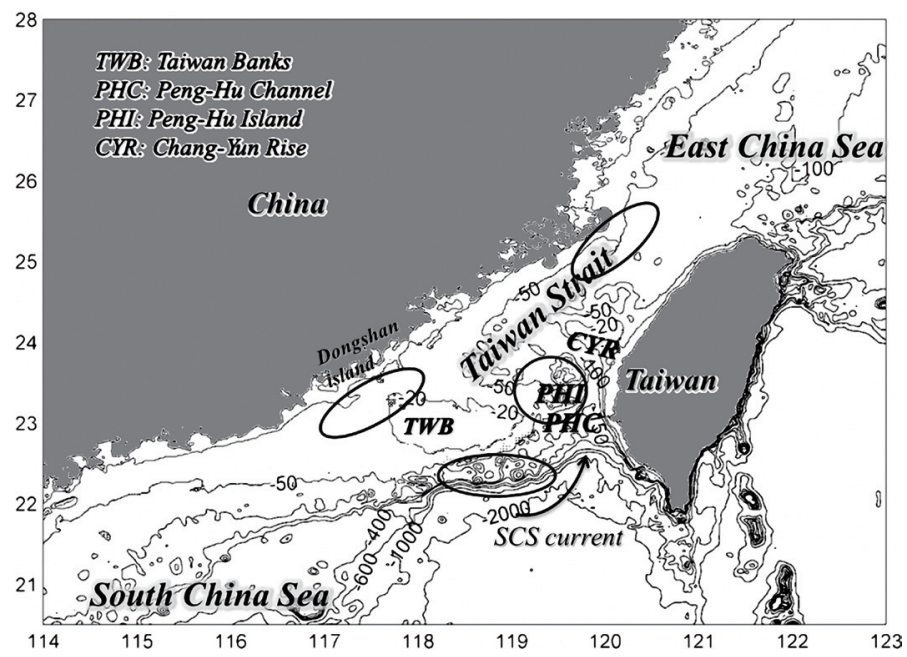

Fig. 1. Topography $(\mathrm{m})$ of the Taiwan Strait (TS). Black circles indicate the schematic position of upwelling regions and the arrow indicates the South China Sea (SCS) current. 
EOF analysis is a statistical method used to decompose a multivariate dataset into its principal components. In EOF analysis satellite SST data were arranged in a two-dimensional array, in an $\mathrm{M} \times \mathrm{N}$ matrix, $\mathrm{T}(\mathrm{x}, \mathrm{t})$, where $\mathrm{M}$ is the number of elements in the spatial dimension and $\mathrm{N}$ is the number of elements in the temporal dimension. The temporal average at each grid point was removed to reveal the features that vary substantially over time to extract detailed information (Paden et al. 1991). The EOF modes were the eigenvectors of the covariance matrix of $\mathrm{T}$ (i.e., $\mathrm{T}^{\mathrm{T}} \mathrm{T}$ ) representing the time averages of the covariance between data collected at various locations. The covariance matrix was decomposed using the singular-value decomposition (SVD) method. $\mathrm{T}^{\mathrm{T}} \mathrm{T}$ can be represented using $\mathrm{VS}^{2} \mathrm{~V}^{\mathrm{T}}$, with the singular values $(\mathrm{S})$ representing the eigenvalues, and the eigenvectors $(\mathrm{V})$ representing the empirical orthogonal modes. Thus, the spatial patterns and time-series variations of SSTs in the eastern TS can be elucidated (Emery and Thomson 2001). This method allows the bulk of the variance in a dataset to be described using a few orthogonal modes and the corresponding timevariation amplitude, which enables the major properties of the dataset to be readily understood.

\section{RESULTS}

Figure 2 displays the 3-month (June - August) mean SST pattern in the TS (1982 - 2012). The SST during the summer was high in the southeast of TS, typically $28-30^{\circ} \mathrm{C}$, and decreased northwestward. The lowest temperature occurred around the China coast, reaching $25-27^{\circ} \mathrm{C}$. Two distinct upwelling regions occurred every year, one along the China coast, and the other southeast of the TWB. The SST in the upwelling region was typically $1-2.5^{\circ} \mathrm{C}$ lower than the temperature in the surrounding area. In certain studies the upwelling region along the China coast has been divided into the southwest upwelling (Dongshan Upwelling) and northwest upwelling regions (Li et al. 1993; Wu et al. 1997). The upwelling around the TWB has occasionally been separated from the upwelling to the south of the Peng-Hu Islands (Hu et al. 2003). Because these upwelling regions are near to each other, distinguishing them using SST images can be a challenge. However, the boundaries of the upwelling region revealed that SST fronts can be accurately detected using an entropy-based edge-detection method (Shimada et al. 2005; Lan et al. 2009). A decadal warming phenomenon was revealed in the summertime SST images and, among them, the coldest three SST patterns were observed in 1982 - 1988. Furthermore, inter-annual variation was substantial. In addition, the spatial variance in the SST was differed substantially between each year. For example, in 1988, the cooling associated with upwelling along the China coast was stronger than the cooling that occurred in the former year (1987) and later year (1990), whereas the SST in other parts of the TS were warmer. Similar variations were also observed in 1997 and 1998. However, during 1990, 1991, 1995, and 1998, the entire TS area appeared to be cooler than average. The detailed long-term variation detected in the June - August SST images is described in the following subsections.

\subsection{Monthly Variation in the Summer}

Figure 3 shows the climatology monthly SST patterns for June, July, and August averaged over the 31-year period from 1982 - 2012. The temperature in the northern and western TS gradually warmed from June - August $\left(>2^{\circ} \mathrm{C}\right)$; whereas that in the southern region, which is the deepest part of the TS, varied less $\left(<1^{\circ} \mathrm{C}\right)$. The upwelling was the strongest in July. This result was reported by Weng et al. (1992), who concluded that the greatest differences in the SST and sea surface salinity between the core and the surrounding water (in July) were $-3.2^{\circ} \mathrm{C}$ and +1.12 , respectively.

Temporal EOF analysis was used to examine the $91 \mathrm{SST}$ images ( 3 months $\times 31$ years -2 omitted months) to explore this monthly transition and its inter-annual change. Figure 4 presents the first EOF mode result which explains $70 \%$ of the total variance. The dominant signal in the corresponding time series was the monthly variation, which depicted warming from June - July, with the warming area distributed in the northwestern strait and the southwestern TWB. By contrast the temperature variation from July - August was small. Jan et al. (2002) reported that the climatology monthly wind stress (1986 - 1995) south of the Penghu Islands changes from northeasterly to southeasterly during May - June, with the maximal monthly southwesterly wind occurring in June and then decaying in July and August. The SST $1^{\text {st }}$ mode EOF pattern shows a retreat from the China Coast Current and participation by the SCS current from the southwestern TS (Fig. 4a). According to Na et al. (1999), the air-sea net heat flux (including solar radiation flux, long-wave radiation flux, sensible heat flux, and latent heat fluxes) in the TS decreases from June, 100 - $110 \mathrm{~W} \mathrm{~m}^{-2}$, to August, 0 - $40 \mathrm{~W} \mathrm{~m}^{-2}$. The air-sea heat exchange as well as the advective heat transport accompanying the SCS current intrusion and the China Coast Current retreat might be main factors for the monthly variation in the first EOF mode variance.

The $1^{\text {st }}$ mode amplitudes for the three months of June, July, and August are depicted separately in Fig. 4b and show significant inter-annual changes. All of the three amplitudes exhibited an obvious warming trend during the 1982 - 2002 period. However, this warming trend was not detected in the past 30 months (June - August, 2003 - 2012). During this 31-year period, sharp transitions in the SST of the TS between June - July frequently occurred. The histogram in Fig. $4 \mathrm{~b}$ represents the deviation from the amplitude exhibited in June to the average observed in July and August. The average histogram value for every 10 years was 98 (1982 - 1991), 122 (1992 - 2001), and 212 (2002 - 2012).

As described in the next subsection, the monthly data 


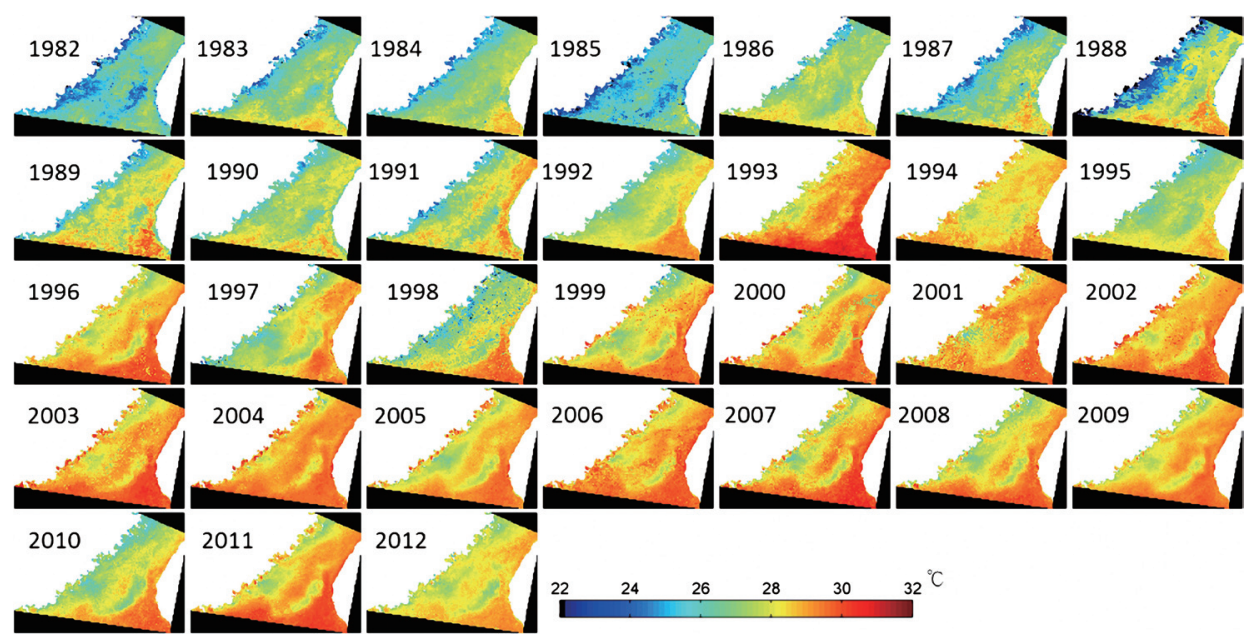

Fig. 2. The three-month (June - August) mean sea surface temperature (SST) $\left({ }^{\circ} \mathrm{C}\right)$ pattern in the TS during $1982-2009$.
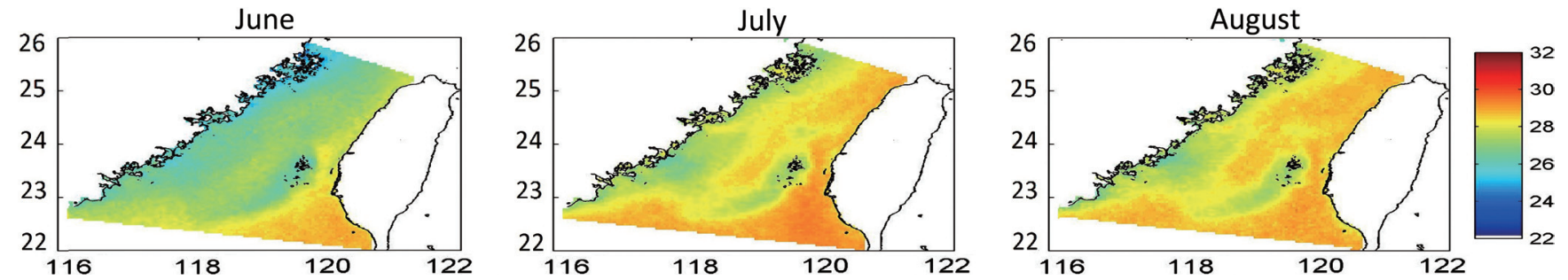

Fig. 3. Monthly SST pattern (31-years mean) obtained for June, July, and August.

(a)

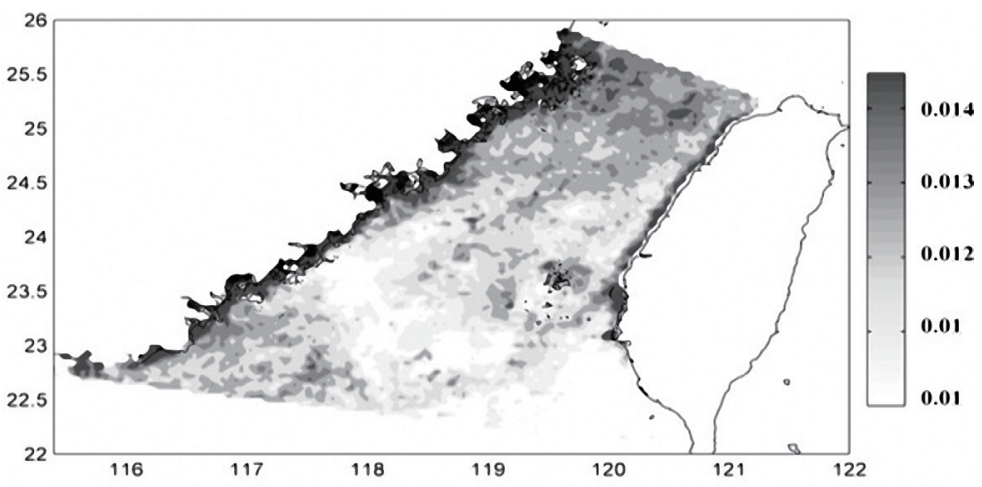

(b)

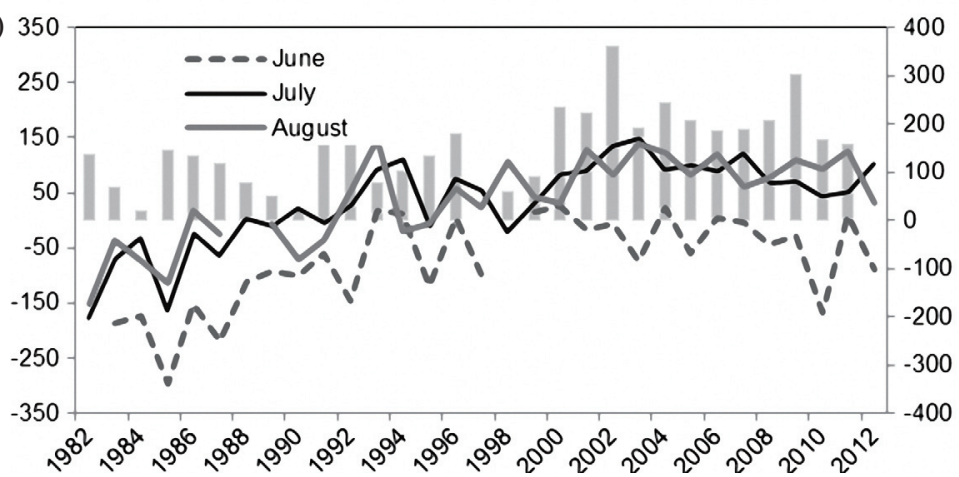

Fig. 4. (a) The $1^{\text {st }}$ empirical orthogonal function (EOF) mode pattern (70\%), note that the data of 91 SST images ( 3 months $\times 31$ years -2 omitted months) were used, and (b) its corresponding time series in which three months were plotted separately (left axis), the histogram represents deviation from amplitude of June to the average of July and August (right axis). 
for July was chosen to represent the mature summertime TS SST phase pattern and the associated upwelling feature.

\subsection{The SST Warming in July}

The first EOF mode pattern result $(71 \%)$ and the corresponding time series obtained using the monthly SST data from July are presented in Fig. 5a. The higher modes were omitted ( 5 and $4 \%$ of the total variance were explained by the second and third modes, respectively). The time series revealed a warming trend. The warming tendency appeared to pause approximately after 2000. The pattern revealed mainly the SST warming spatial distribution. The spatial average of the first mode pattern was 1.05. The warming was typically slow in the western strait offshore area, approximately $0.05^{\circ} \mathrm{C} \mathrm{y}^{-1}$ (divided by a dotted line in Fig. 5b), and fast in the eastern strait and the near-shore area, reaching $0.09^{\circ} \mathrm{C}^{-1}$. This rapid warming on such a small spatial scale indicated that the main cause was heat advection, rather than direct heating from the atmosphere associated with global warming. The warming in the near-shore area might be caused by bias in the pathfinder data collected during the summer, which is discussed in section 4.1. A distinct warming area was detected east of the TWB, where the warming rate reached $0.08^{\circ} \mathrm{C} \mathrm{y}^{-1}$.

The spatial average of the original SST data for July is plotted in Fig. 5b, which shows that a warming trend occurred during 1982 - 2012 at a rate of approximately $0.057^{\circ} \mathrm{C} \mathrm{y}^{-1}$, smaller than the EOF result $\left(0.07^{\circ} \mathrm{C}^{-1}\right)$. The linear warming trend averaged over the study area was slightly lower than that observed in the first EOF mode. In addition, the $\mathrm{R}^{2}$ was smaller in the EOF result. However, based on the statistical test, the regression coefficient between the two results was similar $(\mathrm{z}=.05, p>.05)$. The EOF time series represents the variance of a simple pattern, whereas the original SST time series contained numerous inter-annual signals. The EOF result could be more representative if the dynamic process, which might be related to change in a large-scale circulation, is further verified through numerical model studies and air-sea interaction investigations in future research. The spatial average of the original SST data increased rapidly roughly before 1994. In 1995, the SST was distinctly lower compared with that in 1994, and the inter-annual variations increased substantially thereafter. The increasing trend in the mean SST slowed down during 1994 - 2012, with a rate of only $0.026^{\circ} \mathrm{C} \mathrm{y}^{-1}$. Based on this result, additional information could be obtained if the data is divided into two periods, 1982 - 1993 and 1994 - 2012. The results are presented in the next section.

\subsection{Internal Variability}

Figures $6 \mathrm{a}$ and $\mathrm{b}$ show the plots for two leading modes of EOF applied on the monthly data for July between 1982 -
1993. The first mode explains $77 \%$ of the total variance and it revealed a warming pattern concentrated in the southeastern area. The second and third modes explain only 4.5 and $3.9 \%$ of the total variance. The results for the data obtained after 1994 are shown in Figs. 6c - f. The first mode explains 55\% of the total variance; the pattern and the corresponding time series of the first mode indicate a warming trend. The pattern was similar to that shown in Fig. 5b, except that the warming was stronger southwest of the TS. Considerable warming occurred roughly during 1994 - 2001 and the trend became negative afterwards. The second mode explains $12 \%$ of the total variation. The pattern mainly illustrates a west-to-east out-of-phase distribution, except the TWB upwelling area exhibited the same phase as that of the upwelling area on the eastern Chines coast. The regions with positive values were typically cool areas of the upwelling, as displayed in Fig. 2. The corresponding time series indicated that a large fluctuation occurred during this period (Fig. 6f). Figure $6 \mathrm{f}$ includes the 10-m wind speed $\left(\mathrm{m} \mathrm{s}^{-1}\right)$ observed in July averaged over the area of $23-24^{\circ} \mathrm{N}$ and $118-119^{\circ} \mathrm{E}$, which was the result of both the combined monthly sea surface winds reported by the NOAA (http://www.ncdc.noaa.gov/oa/rsad/air-sea/ seawinds.html\#data) and the Nino 3.4 index (averaged from

(a)

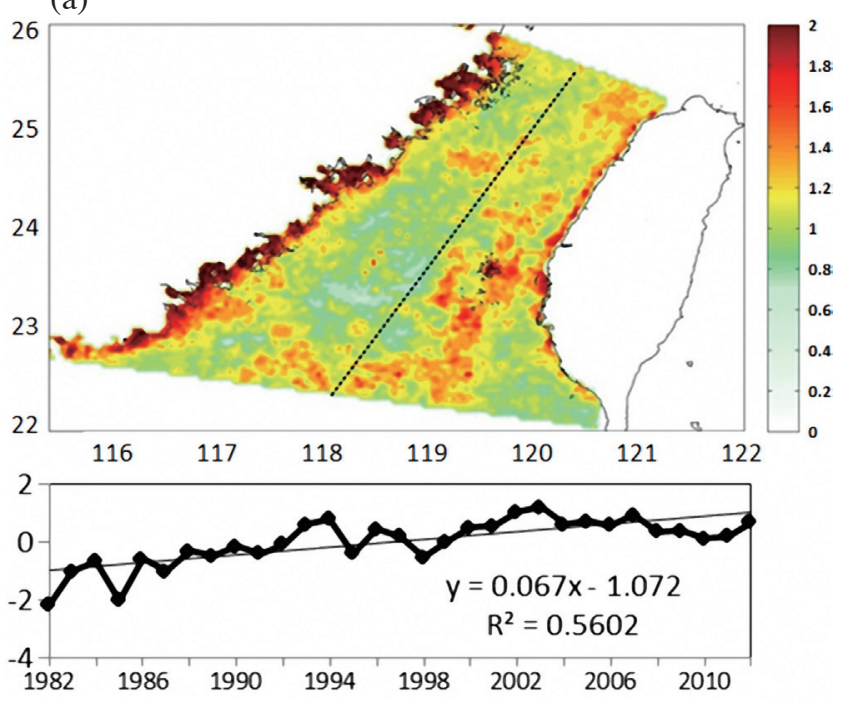

(b)

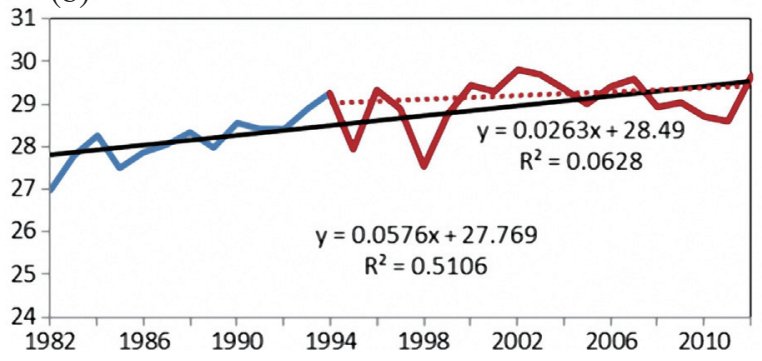

Fig. 5. (a) EOF $1^{\text {st }}$ mode pattern $(71 \%)$ result using the monthly data for July and its corresponding time series. (b) The spatial average of SST during summertime in the TS. 
(a)

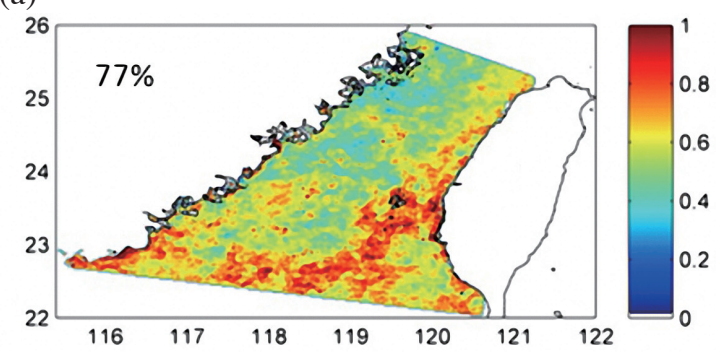

(c)

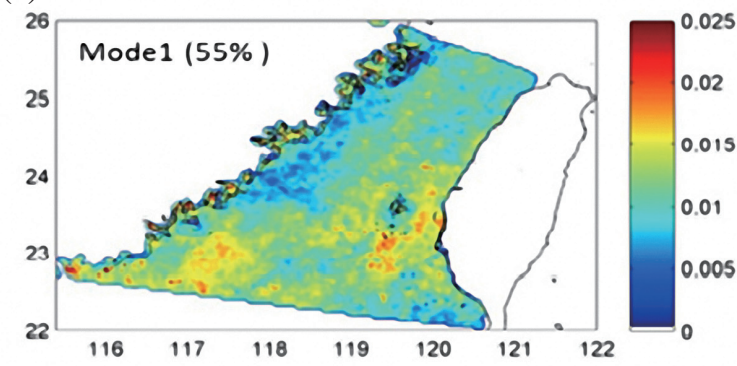

(e)

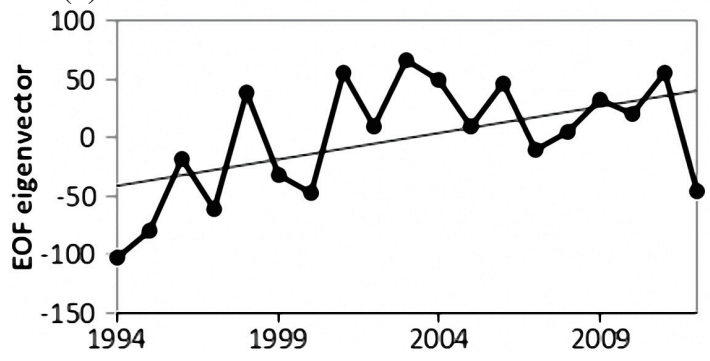

(b)

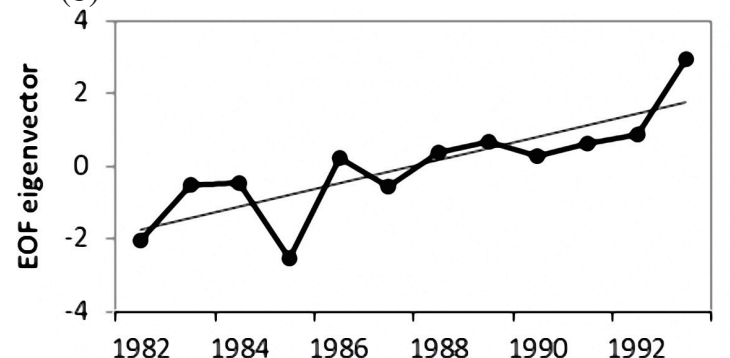

(d)
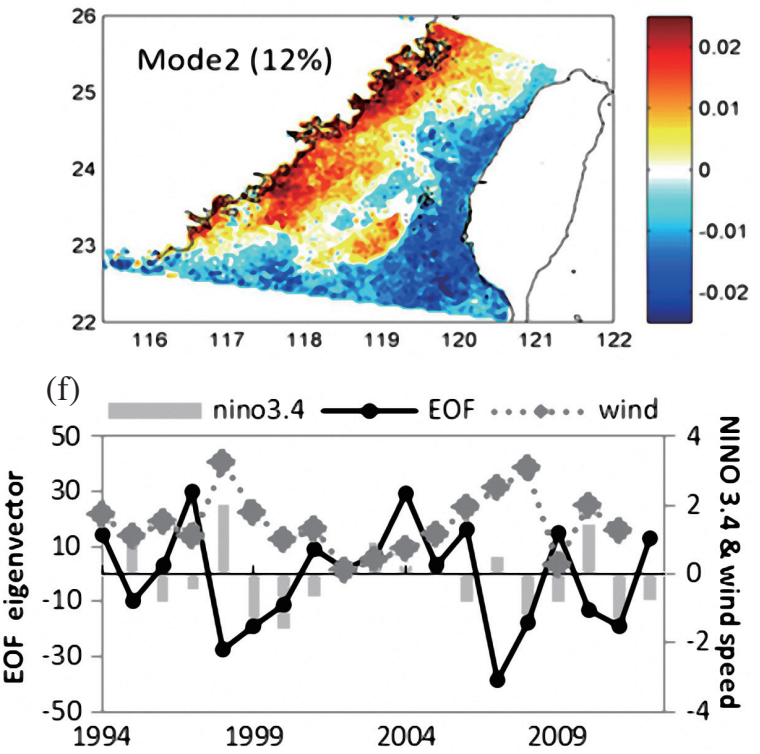

Fig. 6. (a) (b) $1^{\text {st }}$ pattern from the EOF result and its corresponding time series (1982 and 1993). (c) (d) $1^{\text {st }}$ and $2^{\text {nd }}$ pattern from the EOF result, using monthly SST data for July, between 1994 - 2012. (e) The corresponding time series of the $1^{\text {st }}$ mode pattern. (f) The corresponding time series of the $2^{\text {nd }}$ mode pattern, the Nino 3.4 index (averaged from January - March) and the $10 \mathrm{~m}$ wind speed $\left(\mathrm{m} \mathrm{s}^{-1}\right)$ of July averaged in a bounding area $23^{\circ}-24^{\circ} \mathrm{N}$ and $118^{\circ}-119^{\circ} \mathrm{E}$, retrieve from National Oceanic and Atmospheric Administration (NOAA) (http://www.ncdc.noaa.gov/oa/rsad/air-sea/ seawinds.html\#data).

January - March, explained in section 4.2.2). Because the upwelling was either induced or amplified by the southwesterly wind, the strength of the second mode eigenvector was negatively correlated with the wind speed, with an $\mathrm{R}^{2}$ of 0.34 . The three most prominent wind-speed variation peaks are at 1998, 2007, and 2010, and they coincide with the El Niño years. These wind speed peaks caused strong cooling in the upwelling region and warming in the eastern region to occur, as indicated by the second mode eigenvalues and eigenvectors.

\section{DISCUSSION}

\subsection{Decadal Variation in the SST}

The SST spatial average during the summer in the TS indicated that a warming trend occurred during 1982 - 2012. The warming rate was approximately $0.057^{\circ} \mathrm{C} \mathrm{y}^{-1}$, and the spatial distribution of the trend revealed that substantial warming occurred in the southeastern region of the strait, especially in the region surrounding the southeast of TWB. Rapid warming was also displayed in the near-shore regions.
However, a warming bias has recently been identified in the monthly AVHRR Pathfinder data on the near-shore region, and this bias exhibited no correlation with the in situ data collected during the summer in the Eastern Boundary Upwelling Systems (California, Humboldt, Canary, and Benguela) (Dufois et al. 2012). Therefore, additional data are required to determine whether rapid warming occurred in the near-shore region in the TS.

Previous studies did not focus on long-term SST warming in the TS. Long-term SST warming in the northern SCS, which is the source of the water mass flowing in the TS during the summer, has been widely reported. The warming in the northern SCS might contribute to the warming in the southern TS. Fang et al. (2006) used National Centers for Environmental Prediction products to study SST trends during 1993 - 2003 and estimated the decade-long SCS-wide linear SST trend to be $0.050 \pm 0.026^{\circ} \mathrm{C}^{-1}$. They documented a SST linear spatial pattern trend across the SCS and revealed substantially faster warming in the northern SCS. Lima and Wethey (2012) used $1 / 4^{\circ} \times 1 / 4^{\circ}$ daily Optimum Interpolation 
SST version 2 (Reynolds et al. 2007) to study coastal SST globally between 1982 - 2011. Their results indicated rapid warming along the South China coast, but slow warming in the central and southern SCS. In addition to remote sensing data, in situ data have been used to report that the summertime SST has increased in the Taiwan seas in recent decades. Wang et al. (2013) reported a warming rate of $0.03^{\circ} \mathrm{C} \mathrm{y}^{-1}$ during $1985-2001$ in the seas east of China $\left(23-41^{\circ} \mathrm{N}\right.$ and $\left.117-130^{\circ} \mathrm{E}\right)$. Ning et al. (2009) documented environmental changes in the northern SCS during 1976 - 2004 based on repeated oceanographic sections that were collected along a standard line southeast of Hong Kong. They identified conspicuous irregular fluctuations superimposed on long-term trends $\left(0.078^{\circ} \mathrm{C}^{-1}\right)$ in annual SST. Moreover, warming occurred at the surface and in most of the upper 200-m layer. However, the summertime SST warming that occurs in the SCS is generally much smaller than the warming that occurs in the winter (Thompson and Wallace 2001; Belkin et al. 2002; Belkin and Lee 2014). Long-term warming in the subsurface SCS current might cause warming in the TWB upwelling region, where the bottom current flows upslope with the topography, and the bathymetry is deeper than that in other upwelling regions in the TS. Researches have observed substantial climate change in the TS, compared with that in the SCS (Zhang et al. 2010). Tseng et al. (2010) reported a considerable sea-level change that occurred in the regional seas around Taiwan from 1961 - 2003, especially between 1993 - 2003 and the trend was higher than the global rate. Therefore, the summertime warming in the TS might be associated with substantial changes in the circulation.

According to the results from this study the possible SST summertime warming trend in the TS has not been observed in the past 10 years $\left(-0.03^{\circ} \mathrm{C}^{-1}\right.$ during $\left.2002-2012\right)$. In numerous regions around the world the SST has decreased since 1998 (Belkin 2009). This result is in accordance with the global warming phenomenon. According to the observations of Hansen et al. (2010), during the past decade, the global warming rate has decreased considerably with the reduction in global SST warming. Researchers have sought to explain the recent pause (i.e., since 2000) in SST warming. For example, Outten and Esau (2012) identified a band of cooling that has extended across mid-latitude Eurasia during the past decade, and they suggested that this band was related to the loss of Arctic sea ice, which lowers the meridional temperature gradient and causes large-scale atmospheric flow in the Northern Hemisphere.

The long-term SST warming observed in the TS during the summer was distinct from the wintertime warming. Based on long-term (1980 - 2012) AVHRR data, Kuo and Lee (2013) reported rapid wintertime SST warming $\left(0.12^{\circ} \mathrm{C} \mathrm{y}^{-1}\right)$ with the northwestward movement of the SST front, which was caused by the cold China Coastal Current and the warm Kuroshio Branch Current. Oey et al. (2013) suggested that the rapid wintertime warming of shelf seas off the eastern coast of China can contribute to the weakening of the East Asian winter monsoon. Wintertime SST warming occurred the most rapidly in the northern TS (Kuo and Lee 2013), whereas summertime warming was biased to the eastern strait and was relatively weak. However, both the summer and winter warming trends have been stalled over the past 10 years, which were examined in this study.

During 1982 - 2012 the SST transition from June - July exhibited a growing trend, which might be related to the influence of large-scale wind field variation. Yu and Zhou (2007) reported that a change (identified based on the 1980 - 2001 mean minus the 1958 - 1979 mean) in the seasonal onset and northward advance of the East Asian monsoon, from late May to late June, caused the abrupt change in June.

\subsection{Inter-Annual Variability in Upwelling in the TS}

\subsubsection{Factors Influencing Upwelling Strength in the TS}

A component of the mechanism that causes upwelling in the TS is wind-induced coastal upwelling. The East Asian summer monsoon (EASM) is a key factor that influences the strength of the upwelling. In addition, southwesterly wind associated with a typhoon often significantly enhances the upwelling (Kuo et al. 2014; Zheng 2014). Because the topography in the TS is complex and gradually shoals northward, the upwelling along the China coast is considered to be caused by the ascending bottom current (Weng et al. 1992; Huang and Weng 1996). The upwelling mechanism in the east TWB is widely considered to be dominated by the ascending bottom current because it exists year-round, and the southwesterly wind has been reported to play a role in intensifying the upwelling (Hu et al. 2003). Wang and Chern (1992) indicated that the upwelling north of the Peng-Hu Islands is induced by the rise of bottom waters that flow northwestward through the Pengbei Channel, located between the Peng-Hu Islands and the Chang-Yun Rise. Furthermore, tidal mixing has been reported to be a critical factor involved in cooling the upwelling area surface (Guo and Xiu 1992). Collectively, these studies have suggested that the upwelling process in the TS is complex and that studies on the variations in this process should not rely only on satellite SST images. The satellite data does, however, facilitate SST warming identification and the changes in the upwelling phenomenon.

\section{2 .2 Possible Inter-Annual Variations in Upwelling Associated with Climate Variability}

According to the results from the present study, the inter-annual variation increased roughly after 1994. This might have been caused by rapid warming between 1982 - 1993 that masked the inter-annual variability. The exact cause is worth investigating in future studies. The second EOF mode pattern and the corresponding time series (Figs. 6d and f) indicated 
that the temperature variation in the upwelling region was highly correlated with the strength of the southwesterly wind speed, and that the temperature fluctuated considerably. A similar conclusion was reached by Hong et al. (2009), who used a spatial EOF method and presented results indicating the main contribution of spatial variations to SST. Conversely, in this study, the temporal EOF analysis results revealed the temporal variation in SST and the corresponding pattern. However, the wind speed and the EOF eigenvector did not appear to be correlated with the La Niña event.

During the summer, the EASM prevails over the TS and, thus, its inter-annual variability affects the SST in the TS. The El Niño event has been suggested to cause strong southwesterly winds over the northwestern Pacific in the summer (Pan et al. 2002). A time-lagged relationship between the monsoon and ENSO is expected, because ENSO is related to the anomalies of large-scale air-sea interaction in the Pacific and it leads to changes in the low-level pressure field in East Asia by affecting the large-scale ocean-atmosphere interaction. Wang et al. (2001) suggested that the EASM strengthens when El Niño starts to decay. The strong southwesterly wind that occurred in the summer, which was caused by an El Niño onset in the preceding year, increased coastal upwelling and enhanced the northward warm SCS current, similar to the second mode pattern plotted in Fig. 4d. Kuo and Ho (2004) observed that the change in wind patterns in the TS, which might be related to the ENSO events, could modulate the sea surface currents, resulting in an SST change on an inter-annual scale. Hong et al. (2009) reported that a 3-6 month-delayed ENSO effect was likely a major mechanism contributing to the inter-annual variation in coastal upwelling.

However, the strength indicated by the Niño 3.4 index (3 - 6 months in advance) shown in Fig. 6f cannot explain certain wind-speed anomalies. For example, 2007 was not a distinct El Niño year but featured the highest southwesterly wind speed in the period between 1994 - 2012. In 2003 the Niño 3.4 index was higher than that in 2007, but the wind speeds were not notably strong in 2003. Recent studies have determined that the ENSO-EASM relationship can be attributed to the combined effect of the Pacific Decadal Oscillation (PDO) (Chan and Zhou 2005; Chen et al. 2013). ENSO and
PDO comprise similar spatial structures. Generally, the positive/negative PDO period is more likely to coincide with El Niño/La Niña than with La Niña/El Niño, although El Niño/ La Niña years occasionally occur in the negative/positive PDO period. However, the ENSO signals are the strongest in the tropics, whereas the PDO features are most visible in the North Pacific (Hare et al. 1999). In 1998 and 2007 the PDO index (a 5-year running mean) and the Nino 3.4 index were both positive, whereas in 2003, the PDO index was negative (Fig. 7). Chan and Zhou (2005) reported that when PDO and ENSO exist in an in-phase combination (i.e., El Niño/positive PDO or La Niña/negative PDO), the summer monsoon induced rainfall over South China, which is related to EASM intensity, tends to be below or above average, respectively, with an increased frequency. However, in an out-of-phase ENSO-PDO relationship the EASM tends to occur normally. Therefore, the intensity of the subtropical high was suggested to be affected by the two oscillations. However, the mechanism by which PDO affects the atmospheric circulation related to ENSO is complex (Power et al. 1999) and warrants further investigation.

\section{SUMMARY}

This study examined long-term high-resolution satellite data that provided a clear depiction of summertime SST warming and the variations associated with ENSO in the TS. EOF analysis on the 1982 - 2012 data revealed one major mode, which explained the SST warming trend. Warming occurred primarily in the eastern TS and reached a rate of $0.065-0.09^{\circ} \mathrm{C}^{-1}$, whereas in the western region of the strait, the warming rate was only $0.05^{\circ} \mathrm{C}^{-1}$. However, during the studied past 10 years the warming phenomenon was not apparent and an average cooling rate of $-0.03^{\circ} \mathrm{C}^{-1}$ was measured. The monthly transition in the SST from June - July also became increasingly sharp.

The study results indicate that the warming slowed down in the recent 10 - 15 years and considerable interannual variation occurred in the period after 1994. EOF results applied on the data between 1982 - 1993 showed $77 \%$ of the total variance was explained by the $1^{\text {st }}$ mode,

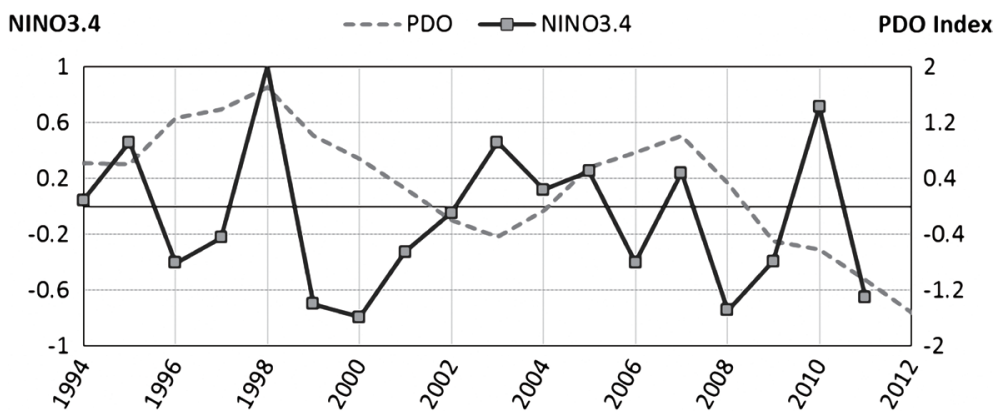

Fig. 7. The Pacific Decadal Oscillation (PDO) index (averaged from January - March) and Nino 3.4 index (averaged from January - March). 
inferring the warming pattern. The second $(4.5 \%)$ and third modes $(3.9 \%)$ were negligible. EOF results applied on the data between 1994 - 2012 showed that the first EOF mode $(55 \%)$ revealed the warming pattern, whereas the second EOF mode revealed a pattern (12\%) that explained the interannual variation in the SST, which was strongly correlated with the wind speed. Strengthening winds have enhanced the upwelling along the China coast, eastern TWB, and the region south of the Peng-Hu Islands, whereas the eastern TS has become increasingly warm because of the increased transport of warm SCS water. The inter-annual variation in the southwesterly wind can be affected by both ENSO and the background PDO phase. The strongest upwelling in the TS associated with southwesterly wind typically occurs when ENSO and PDO are in phase.

Acknowledgements This study was part of the Taiwan integrated research program on Climate Change Adaptation Technology (TaiCCAT), sponsored by grants from the Ministry of Science and Technology of Taiwan, MOST 1012625-M-019-006 and 102-2811-M-019-001.

\section{REFERENCES}

Belkin, I., R. Krishfield, and S. Honjo, 2002: Decadal variability of the North Pacific Polar Front: Subsurface warming versus surface cooling. Geophys. Res. Lett., 29, 65-1-65-4, doi: 10.1029/2001GL013806. [Link]

Belkin, I. M., 2009: Rapid warming of Large Marine Ecosystems. Prog. Oceanogr., 81, 207-213, doi: 10.1016/j. pocean.2009.04.011. [Link]

Belkin, I. M. and M. A. Lee, 2014: Long-term variability of sea surface temperature in Taiwan Strait. Clim. Change, 124, 821-834, doi: 10.1007/s10584-0141121-4. [Link]

Chan, J. C. L. and W. Zhou, 2005: PDO, ENSO and the early summer monsoon rainfall over south China. Geophys. Res. Lett., 32, L08810, doi: 10.1029/2004GL022015. [Link]

Chen, W., J. Feng, and R. Wu, 2013: Roles of ENSO and PDO in the link of the East Asian winter monsoon to the following summer monsoon. J. Climate, 26, 622635, doi: 10.1175/JCLI-D-12-00021.1. [Link]

Dufois, F., P. Penven, C. P. Whittle, and J. Veitch, 2012: On the warm nearshore bias in Pathfinder monthly SST products over Eastern Boundary Upwelling Systems. Ocean Model., 47, 113-118, doi: 10.1016/j.ocemod.2012.01.007. [Link]

Emery, W. J. and R. E. Thomson, 2001: Data Analysis Methods in Physical Oceanography, Elsevier Science, 319-343.

Fang, G., H. Chen, Z. Wei, Y. Wang, X. Wang, and C. Li, 2006: Trends and interannual variability of the South China Sea surface winds, surface height, and surface temperature in the recent decade. J. Geophys. Res., 111, C11S16, doi: 10.1029/2005JC003276. [Link]

Guo, B. H. and X. M. Xiu, 1992: Warm water over Taiwan shoal and surrounding cold water ring in early summer. J. Oceanog. Taiw. Str., 11, 95-100. (in Chinese)

Hansen, J., R. Ruedy, M. Sato, and K. Lo, 2010: Global surface temperature change. Rev. Geophys., 48, RG4004, doi: 10.1029/2010RG000345. [Link]

Hare, S. R, N. J. Mantua, and R. C. Francis, 1999: Inverse production regimes: Alaska and West Coast Pacific salmon. Fisheries, 24, 6-14, doi: 10.1577/1548-8446(1 999)024<0006:IPR>2.0.CO;2. [Link]

Hong, H., S. Qiu, W. Ruan, and Q. Hong, 1991: MinnanTaiwan Bank Fishing Ground Upwelling Ecosystem Study, Science Publishing Housing, Beijing, China.

Hong, H., C. Zhang, S. Shang, B. Huang, Y. Li, X. Li, and S. Zhang, 2009: Interannual variability of summer coastal upwelling in the Taiwan Strait. Cont. Shelf Res., 29, 479-484, doi: 10.1016/j.csr.2008.11.007. [Link]

Hu, J., H. Kawamura, H. Hong, and W. Pan, 2003: A review of research on the upwelling in the Taiwan Strait. $B$. Mar. Sci., 73, 605-628.

Huang, R. and X. Weng, 1996: The characteristics and cause analyses of the upwelling in the coastal area of central Fujian. Trop. Oceanol., 15, 52-59. (in Chinese)

Jan, S., J. Wang, C. S. Chern, and S. Y. Chao, 2002: Seasonal variation of the circulation in the Taiwan Strait. J. Mar. Syst., 35, 249-268, doi: 10.1016/S09247963(02)00130-6. [Link]

Jan, S., D. D. Sheu, and H. M. Kuo, 2006: Water mass and throughflow transport variability in the Taiwan Strait. J. Geophys. Res., 111, C12012, doi: 10.1029/2006JC003656. [Link]

Kuo, N. J. and C. R. Ho, 2004: ENSO effect on the sea surface wind and sea surface temperature in the Taiwan Strait. Geophys. Res. Lett., 31, L13309, doi: 10.1029/2004GL020303. [Link]

Kuo, Y. C. and M. A. Lee, 2013: Decadal variation of wintertime Sea Surface Temperature in the Taiwan Strait. J.Mar.Sci.Technol., 21, 117-123, doi: 10.6119/JMST013-1219-9. [Link]

Kuo, Y. C., M. A. Lee, and C. C. Chern, 2014: Typhooninduced ocean responses off the southwest coast of Taiwan. Ocean Dyn., 64, 1569-1581, doi: 10.1007/ s10236-014-0776-8. [Link]

Lan, K. W., H. Kawamura, M. A. Lee, Y. Chang, J. W. Chan, and C. H. Liao, 2009: Summertime sea surface temperature fronts associated with upwelling around the Taiwan Bank. Cont. Shelf Res., 29, 903-910, doi: 10.1016/j.csr.2009.01.015. [Link]

Lee, M. A., Y.Chang, F. Sakaida, H. Kawamura, C. H. Cheng, J. W. Chan, and I. Huang, 2005: Validation of satellitederived sea surface temperatures for waters around Taiwan. Terr. Atmos. Ocean. Sci., 16, 1189-1204. 
Li, R. F., Q. C. Zeng, Z. J. Gan, and W. Z. Wang, 1993: Numerical simulation of South China Sea warm current and currents in Taiwan Strait in winter. Prog. in Nat. Sci., 3, 21-25. (in Chinese)

Lima, F. P. and D. S. Wethey, 2012: Three decades of highresolution coastal sea surface temperatures reveal more than warming. Nat. Commun., 3, 1-13, doi: 10.1038/ ncomms1713. [Link]

McClain, E. P., W. G. Pichel, and C. C. Walton, 1985: Comparative performance of AVHRR-based multichannel sea surface temperatures. J. Geophys. Res., 90, 1158711601, doi: 10.1029/JC090iC06p11587. [Link]

Na, J., J. Seo, and H. J. Lie, 1999: Annual and seasonal variations of the sea surface heat fluxes in the East Asian marginal seas. J. Oceanogr., 55, 257-270, doi: 10.1023/A:1007891608585. [Link]

Ning, X., C. Lin, Q. Hao, C. Liu, F. Le, and J. Shi, 2009: Long term changes in the ecosystem in the northern South China Sea during 1976-2004. Biogeosciences, 6, 2227-2243, doi: 10.5194/bg-6-2227-2009. [Link]

Oey, L. Y., M. C. Chang, Y. L. Chang, Y. C. Lin, and F. H. $\mathrm{Xu}, 2013$ : Decadal warming of coastal China Seas and coupling with winter monsoon and currents. Geophys. Res.Lett.,40,6288-6292,doi: 10.1002/2013GL058202. [Link]

Outten, S. D. and I. Esau, 2012: A link between Arctic sea ice and recent cooling trends over Eurasia. Clim. Change, 110, 1069-1075, doi: 10.1007/s10584-0110334-z. [Link]

Paden, C. A., M. R. Abbott, and C. D. Winant, 1991: Tidal and atmospheric forcing of the upper ocean in the Gulf of California: 1. Sea surface temperature variability. J. Geophys. Res., 96, 18337-18359, doi: 10.1029/91JC01597. [Link]

Pan, J., X. H. Yan, Q. Zheng, W. T. Liu, and V. V. Klemas, 2002: Interpretation of scatterometer ocean surface wind vector EOFs over the Northwestern Pacific. Remote Sens. Environ., 84, 53-68, doi: 10.1016/S00344257(02)00073-1. [Link]

Power, S., T. Casey, C. Folland, A. Colman, and V. Mehta, 1999: Inter-decadal modulation of the impact of ENSO on Australia. Climate Dyn., 15, 319-324, doi: 10.1007/ s003820050284. [Link]

Reynolds, R. W., T. M. Smith, C. Liu, D. B. Chelton, K. S. Casey, and M. G. Schlax, 2007: Daily high-resolutionblended analyses for sea surface temperature. J. Climate, 20, 5473-5496, doi: 10.1175/2007JCLI1824.1. [Link]

Sakaida, F. and H. Kawamura, 1992: Accuracies of NOAA/ NESDIS sea surface temperature estimation technique in the oceans around Japan. J. Oceanogr., 48, 345-351, doi: 10.1007/BF02233992. [Link]

Shimada, T., F. Sakaida, H. Kawamura, and T. Okumura, 2005: Application of an edge detection method to sat- ellite images for distinguishing sea surface temperature fronts near the Japanese coast. Remote Sens. Environ., 98, 21-34, doi: 10.1016/j.rse.2005.05.018. [Link]

Tang, D. L., D. R. Kester, I. H. Ni, H. Kawamura, and H. Hong, 2002: Upwelling in the Taiwan Strait during the summer monsoon detected by satellite and shipboard measurements. Remote Sens. Environ., 83, 457-471, doi: 10.1016/S0034-4257(02)00062-7. [Link]

Tang, D. L., H. Kawamura, and L. Guan, 2004: Long-time observation of annual variation of Taiwan Strait upwelling in summer season. Adv. Space Res., 33, 307312, doi: 10.1016/S0273-1177(03)00477-0. [Link]

Thompson, D. W. J. and J. M. Wallace, 2001: Regional climate impacts of the Northern Hemisphere annular mode. Science, 293, 85-89, doi: 10.1126/science.1058958. [Link]

Tseng, Y. H., L. C. Breaker, and E. T. Y. Chang, 2010: Sea level variations in the regional seas around Taiwan. $J$. Oceanogr., 66, 27-39, doi: 10.1007/s10872-010-00032. [Link]

Wang, F., Q. Meng, X. Tang, and D. Hu, 2013: The longterm variability of sea surface temperature in the seas east of China in the past 40 a. Acta Oceanol. Sin., 32, 48-53, doi: 10.1007/s13131-013-0288-2. [Link]

Wang, J. and C. S. Chern, 1992: On the distribution of bottom cold waters in Taiwan Strait during summertime. La mer, 30, 213-221.

Wang, Y., B. Wang, and J. H. Oh, 2001: Impact of the preceding El Niño on the East Asian summer atmosphere circulation. J. Meteorol. Soc. Jpn., 79, 575-588.

Weng, X., Q. Zhang, T. Yan, C. Wang, and H. Liang, 1992: Analysis of water masses in the middle and northern Taiwan Strait in spring and summer. Oceanol.Limnol. Sin., 23, 235-244. (in Chinese)

Wu, C. R. and Y. C. Hsin, 2005: Volume transport through the Taiwan Strait: A numerical study. Terr. Atmos. Ocean. Sci., 16, 377-391.

Wu, Y., X. Weng, and Y. Yang, 1997: Analysis on causes of generation, evolution and decay process of upwellings off the western coast of Taiwan Strait. Stud.Mar. Sin., 38, 53-59. (in Chinese)

Yu, R. and T. Zhou, 2007: Seasonality and three-dimensional structure of interdecadal change in the East Asian monsoon. J. Climate, 20, 5344-5355, doi: 10.1175/2007JCLI1559.1. [Link]

Zhang, L., L. Wu, X. Lin, and D. Wu, 2010: Modes and mechanisms of sea surface temperature low-frequency variations over the coastal China seas. J. Geophys. Res., 115, C08031, doi: 10.1029/2009JC006025. [Link]

Zheng, Z. W., 2014: Unusual warming in the coastal region of northern South China Sea and its impact on the sudden intensification of tropical cyclone Tembin (2012). Adv. Meteorol., 2014, doi: 10.1155/2014/250752. [Link] 